\title{
The regional accelerator as a driver for the development of an innovative environment and technological entrepreneurship
}

\author{
Anna Ovchinnikova ${ }^{1 *}$, Tatyana Topoleva ${ }^{1}$ \\ ${ }^{1}$ Udmurt branch of Institute of Economics of Ural Branch of Russian Academy of Science, 4, Lomonosov st., Izhevsk, 426004, \\ Russia
}

\begin{abstract}
Development of the innovative economy in Russia predetermines the need to adapt to new challenges and global economic trends. World experience demonstrates the effectiveness of the acceleration mechanism in supporting innovative projects, expanding the network interaction of the elements of innovative ecosystems, and accelerating the implementation of breakthrough ideas. The existing imbalance in the socio-economic development of the Russian regions, the differentiation of their resource potentials determine the search for institutional solutions that activate the innovation process. The conceptual and methodological basis for acceleration platforms and foreign and domestic experience of business accelerators are analyzed. The stages of change management in the context of acceleration logic are systematized. These are hackathon, foresight, acceleration, project development. The article substantiates the expediency of acceleration of innovations in the Udmurt Republic as an institutional element of the innovative environment that meets the specifics of the military-industrial complex, the declared diversification of defense industries and actualization of the request to increase the share of hightech civilian products in the total volume. The mission and goals of the accelerator and the main program stages are described. The graphical model of a regional accelerator is presented. It integrates key elements of the innovation environment. The result is stimulation of the innovation process, support of the technological entrepreneurship, strong regional innovative competencies, qualitative growth of project activities, which will significantly increase the level of competitiveness of regional enterprises and the role of the region in the global economic system.
\end{abstract}

\section{Introduction}

In the context of the innovative economy, in order to achieve the technological leadership in the international arena, it is necessary to overcome the communication gap between the subjects of innovation activities, significantly increasing the level of interaction in the "science (innovators) - business - government" triad. The focus on structural changes in the national and regional economic systems actualizes the need to improve mechanisms, methods and tools for innovation, as well as to stimulate the motivation and competencies of innovators to generate and commercialize new ideas. Innovative activity is expressed in the reproduction of the intellectual component of an innovative product and in the ability to manage it qualitatively. In the institutional structure of successful commercialization of the results of innovative activities, one of the most effective elements are business accelerators - systems for supporting innovative projects at the initial stages. Acceleration programs carry out technological scouting, transform the level of participants, increase the adaptive abilities of companies, opening up objective opportunities for leapfrogging development and strengthening competitive advantages.

\section{Materials and methods}

The authors used the results of works describing the world and domestic experience of business accelerators. One of the first theoretical and methodological substantiation of the phenomenon of acceleration was provided by J.D. Christiansen in his work Copying $Y$ Combinator: a framework for developing seed accelerator programs, describing a business accelerator as a startup support program characterized by such features as the transparency of selection for participation, support, investment in exchange for a share in the charter capital of companies at the pre-sowing and sowing stages, project consulting, team work [1]. The issues of intensification of the technological transfer in the context of acceleration programs are described by K. Malek, N. Radojevich-Kelly, I. McCarthy, D. Hoffman, P. Miller, K. Bound, M. Szafranski [2-6]. The mechanism of acceleration of innovative projects has been analyzed by H. Etzkowitz, J. Pique, C. Scheel, and J. BerbegalMirabent [7-9]. The domestic vector of research is represented by the works by S. Makarov, A.A. Sytnik, M.A. Kamenskikh [10-12]. O.A. Zhdanova views business accelerators as an institution of the venture capital system, paying particular attention to the business model and marketing strategy [13]. Yu.V. Fedorov and 
A.V. Tsvetnykh define it as a form of integrated entrepreneurial activity aimed to support innovations and as an element of the regional innovation infrastructure that provides partner support for project commercialization [14]. M.R. Kozlov defines a business accelerator as a type of business incubator formed as a result of the focus of corporations on the selection of the most promising startups [15]. Characteristics of the regional acceleration process are presented by D.A. Statovsky who defines it as a tool or a set of principles in the arsenal of the subject of innovation (development institution) aimed at increasing the efficiency of the regional technological transfer. The hypothesis about the unification of the acceleration toolkit has been made forward in [16].

The authors used the general scientific methods, including: comparative and structural analysis, classification and typology, abstraction, generalization, and graphic visualization.

\section{Results}

At the national level, business accelerators perform a number of functions that facilitate innovation processes, including:

- increasing the systemic efficiency of development institutions at the federal and regional levels;

- involving the corporate sector in acceleration programs;

- promoting the development of social entrepreneurship [17].

A business accelerator is an organizational model for the accelerated development of startups through the investment, mentoring and expert support for early stage projects. Within the accelerator, structured practiceoriented programs are implemented. They allow participants to "grow" business models, improve professional skills, form a business strategy, obtain investments and increase economic performance.

In the mid-2000s, the concept of business acceleration (as opposed to business incubation) was proposed in order to promote projects. The first accelerator "YCombinator" was created in 2005 in the USA by P. Graham and D. Livingston. Until 2014, the investment conditions were as follows: \$17,000 for a 7\% stake and additional $\$ 80,000$ converted into a stake, depending on the results of the next round of investments. Currently, seed investment is $\$ 150$ thousand for a share of $7 \%$ [18]. The average business value of companies that implemented the Y-Combinator program exceeded \$ 100 billion, which determines the image effect and positions its graduates as particularly attractive to the investors.
According to the developers, the amount of seed funding is not a determining factor for acceleration participants, but it allows teams to concentrate efforts on project activities and cover the basic costs of startups. Among the most famous American business accelerators are Techstars, Plug and Play, 500 Startups, Alchemist, Techstarts, Angelpad, FoodX, and Coplex.

In Europe, the first business accelerator "Seedcamp" appeared in the UK in 2007. More than 380 startups have implemented acceleration programs on its platform, the investments of the world's leading investors have exceeded \$ 5 billion [19]. Currently, over 50 business accelerators operate in Europe, including: Startupbootcamp, Lanzadera Accelerator, Future Fifty, Barclays, Entrepreneur First, Wilco, and others. Research on the startup support scale indicates the proportionality of the American and European innovation ecosystems [20]. Intensive growth of business accelerators is also observed in Asian countries, where their number is more than 100. According to various estimates, there are 500-700 business accelerators in the world; in 2019, the number of acceleration programs reached 2,191 thousand dollars; in Canada and Great Britain - 250 thousand dollars.

The acceleration logic provides for several stages of change management (Fig. 1): hackathon, foresight, acceleration and post-acceleration. The hackathon is an element of crowdsourcing of ideas and the starting point for successful projects. The most important components are interaction with mentors and technical specialists, new knowledge about technologies, taking into account tasks of innovators. Within the foresight sessions, the market needs are actualized, strategies for the participants of the innovation process are developed. At this stage, the circle of experts, interested investors and industrial partners is determined. The pre-acceleration stage is an additional service for the commercialization of projects and business plans. It is useful for teams that have not yet decided on a direction of movement and need some refinement of ideas. Pre-acceleration is aimed at popularizing innovative activities; a wide range of participants can be involved in this process (creative youth, students, young researchers, technology teams, representatives of science-intensive companies).

The acceleration program is implemented directly, including the preparatory and active stages, as a result of which the best accelerator projects are selected 3-8 months later. At the post-acceleration stage, expert consulting, project promotion and business scaling are accompanied by personal facilitators. 


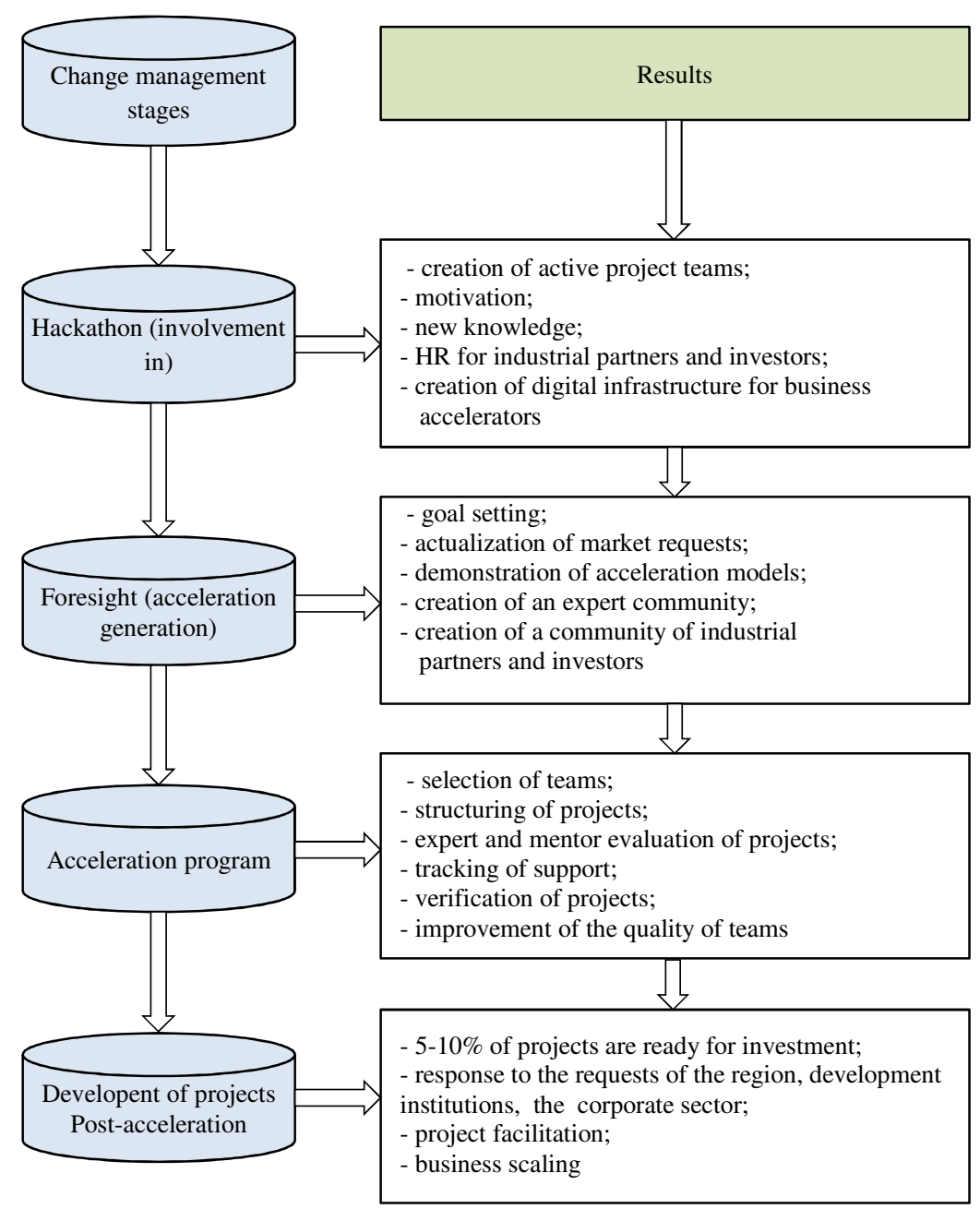

Figure 1. Stages of change management in acceleration logic.

The specific feature of the Russian innovation ecosystem is a predominance of the government component (grant programs, fund support for startups in investment rounds " $\mathrm{A}$ " and "B"). A significant share of the infrastructure support is entrusted to federal development institutions. Business accelerators were created later than in Western countries - in 2009; at the initial stage, IT projects were promoted. Currently, there are the following types of accelerators: corporate accelerators, private accelerators, accelerators with public capital, university accelerators and regional accelerators.

The largest Russian accelerators are GenerationS, Pulsar Venture, Accelerator of the Internet Initiatives Development Fund (IIDF), Skolkovo. In 2013-2020, more than 16 thousand startups took part in acceleration programs by "GenerationS", more than 10 thousand took part in acceleration programs by "IIDF", more than 2 thousand took part in acceleration programs by "Skolkovo". "GenerationS" is an accelerator with public capital that does not invest in startups, but facilitates communications with the corporate sector, with an impressive prize pool of industrial partners. The "IIDF Accelerator" operates at the regional level; up to $50 \%$ of the total number of transactions are carried out with regional startups in IT, retail, financial technologies. Interests of the accelerator in the share of companies vary within 3-7\%; when the KPI is reached, investments in technology startups increase significantly; for example, round " $\mathrm{A}$ " involves financing in the amount of over 300 million rubles. [21].

The leading Russian universities have also initiated acceleration programs: Captains of Russia at the REU n.a. G.V. Plekhanov, IT Accelerator at the Ural Federal University, Ideal Machine at St. Petersburg National Research University of Information Technologies, Mechanics and Optics, etc. In 2020, the acceleration program of the Higher School of Economics ranked first in the world ranking of university accelerators $U B I$ Global [22].

The corporate sector develops its own acceleration programs within a given specialization and tasks related to the growth of companies' capitalization achieved through the acquisition of new technologies that allow for occupying adjacent market niches, as well as for optimizing business processes, reducing costs, promoting internal projects, attracting new clients. Among the corporate accelerators are "Accelerator of Sberbank", "KAMAZ-digital", "Accelerator of NCO Nornickel", "MTS Startup Hub", "Severstal SteelTech 
Accelerator", "Goznak Startup Lab". In 2020, 14 new corporate accelerators were launched, more than $30 \%$ of acceleration programs were ordered by the banking sector and food retailers (Fig. 2).

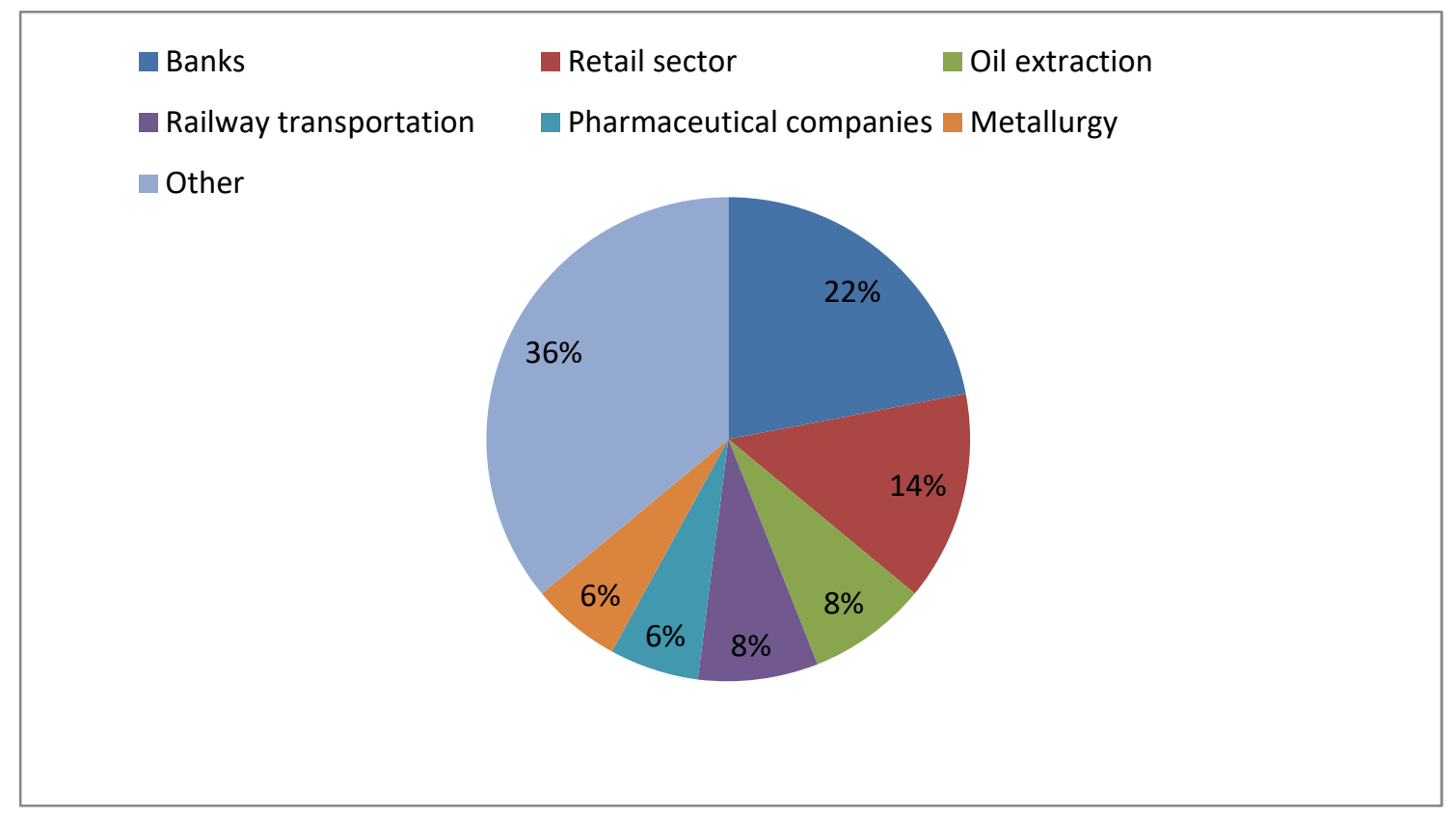

Figure 2. Distribution of corporate acceleration programs by industry in 2020 .

In the context of geopolitical tensions, since 2019, the West has a negative attitude to the Russian capital. Startups with a high share of Russian transactions have been closed; in 2020, this problem spread to funds working in conjunction with business accelerators and the investment sector.

In 2020, the Covid-19 pandemic had a negative impact on all sectors of the economy, including the innovation sector. According to the Dsight study "Venture Russia - 2020", some of the acceleration programs were suspended [23]. Most business accelerators have changed the format of their activities, moving to the online space. Analysis of innovative solutions revealed a demand for technologies that are more likely to be relevant in the long term - Digital twins, IoT, BigData, Industrial Tech, robotization, biometrics, Hyperautomation, AR / VR, Healthcare. In 2018, 107 transactions of Russian accelerators with technology startups were concluded in the amount of 466.8 million rubles; in 2020, the downward trend remained. 16 contracts were concluded [24].

Summarizing the results of the activities of business accelerators, it is possible to formulate the main advantages characteristic of this organizational model:

- Building the potential of innovative entrepreneurship through the mentoring support.

The main stages of training involve the participation of mentors - qualified consultants accompanying the projects. According to the founder of LinkedIn R. Hoffman: "Initiating a startup is like throwing yourself off a cliff and trying to assemble an airplane during the flight down. A mentor is a person who has already assembled an airplane and will help others to do it" [25]. The largest business accelerators define mentoring as a key competence when working with startups. The training block includes the improvement of entrepreneurial skills in the following areas: business planning, legal and accounting, management, financing, work with personnel and clients, negotiation. The educational context of acceleration is of great public importance.

- Decrease in transaction costs, access to resource bases.

Since within the acceleration programs, the interaction of participants with representatives of the expert community, industrial partners, and potential consumers is intensifying, the information asymmetry is leveling: startups immediately "connect" to reliable resources, bypassing the stages of search and verification. On the other hand, resource suppliers can focus on the most promising projects. Thus, transaction costs are reduced on both the demand and supply sides.

- Effective use of investments from the public and corporate sectors.

By screening out unproductive ideas, business accelerators help minimize government expenditures intended to support unpromising venture capital projects. Likewise, entrepreneurs (investors) and innovators save time and resources through the rapid market validation which can help to select really valuable ideas, improve or abandon them at no cost. In addition, in recent years, the level of understanding of market mechanisms has significantly increased among the investors.

An effective approach to innovation management is largely due to the knowledge of the laws of the innovation cycle - a process of logically interrelated stages, including:

- creating a business idea, $R \& D$;

- prototyping an innovative product;

- seed financing, prototype improvement;

- investing in an innovative project; 
- entering the market;

- increasing sales volumes;

- achieving sales stabilization;

- bifurcation (modernization or assortment changes).

In the infrastructure system intended for supporting innovation, business accelerators are usually involved in the first four stages of the innovation cycle, which is an undoubted advantage for innovators in the face of a lack of knowledge, experience in the investment market and start-up resources for implementing technological ideas.

The uneven development of regional economic systems reflects the lag in innovation trends both in institutional and infrastructural aspects. Currently, 52\% of regional accelerators are located in Moscow and Moscow region, 5.8\% - in the Republic of Tatarstan, 5\% - in St. Petersburg and Leningrad region, 4\% - in Sverdlovsk region. Of the total number of accelerators, $5 \%$ were created under the program of the Presidential Grants Fund. The most successful regional business accelerators are TechStarter (Voronezh), the Regional Acceleration Program of the Republic of Bashkortostan (Ufa), A-Start (Novosibirsk), SturtupSamara (Samara), Big Intelligence ( Perm). In more than 50 regions of the Russian Federation, there is no this element of the innovation environment [26].

In the context of the underdeveloped domestic venture capital market, most regional accelerators do not finance innovative startups. They set a fixed fee for acceleration services, thereby minimizing market risks. In the structure of investment in innovative startups, the share of accelerators does not exceed $2 \%$ (Fig. 2) [27]. There is a trend towards an outflow of innovative ideas from the regions to the federal sites, or to the regions with a developed innovation infrastructure. This aggravates regional disproportions, affecting the innovative potential of the territories.

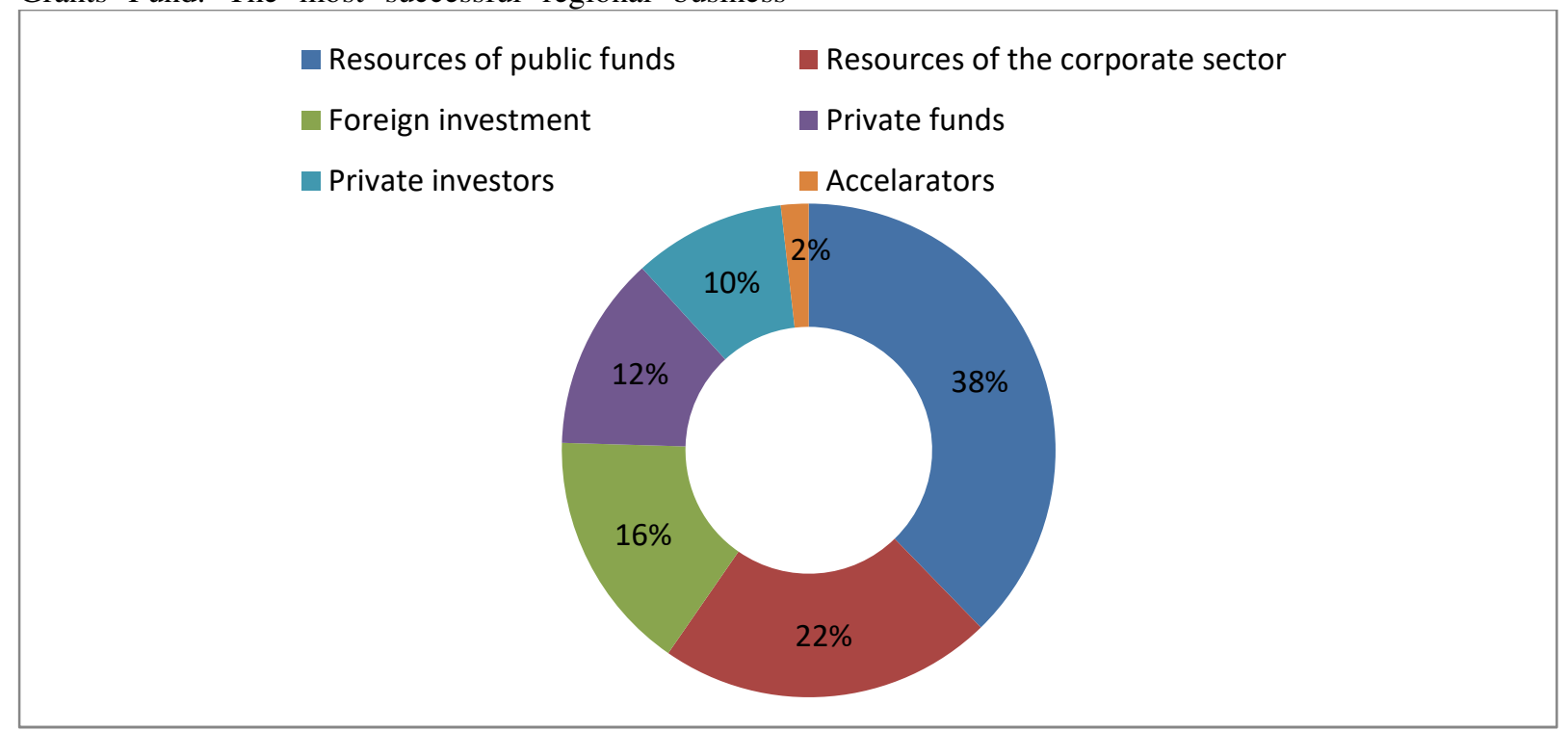

Figure 3. The structure of investments in innovative start-ups in Russia.

Currently, in the Udmurt Republic, with the assistance of the UR Development Corporation and the UR Export Support Center, two acceleration programs are being implemented. The export accelerator has trained five teams in the following tracks: IT, mechanical engineering, agriculture and food industry. The result was contracts concluded with foreign companies from the USA, Spain, Bulgaria, Venezuela, Kazakhstan, Belarus, and Moldova. The winners received 500 thousand rubles to conduct marketing research, create exhibition stands and promote projects online. Interaction with teams continues in a postacceleration format.

In order to develop a model of the regional accelerator of innovations for the Udmurt Republic, it is necessary to analyze features of the innovative development of the region. Currently, the republic is forming an innovation ecosystem [28-32]. As of the beginning of 2020, 30 organizations are involved in R\&D, of which $20 \%$ belong to public organizations, $33.3 \%$ are companies, and $36.6 \%$ are higher education organizations. The region has a high level of scientific and technical potential, the fundamental block of research is coordinated by the Udmurt Federal Research Center of the Ural Branch of the Russian Academy of Sciences, which includes: agricultural and humanitarian subdivisions. Studies of the socio-economic problems are carried out by the Udmurt branch of the Institute of Economics of the Ural Branch of the Russian Academy of Sciences.

Over the past five years, there has been a positive trend in the number of personnel engaged in research and development which has increased by $19 \%$ (2036 people). The number of production technologies used increased by $33 \%$ and amounted to 6642 units. In 2019, the innovative activity of organizations reached the level of $10.6 \%$, which is $3.5 \%$ higher than in the previous period. At the same time, a number of critical trends have been observed: a decline in the cost of technological innovation of organizations - 5156.1 million rubles. (a 55\% drop by 2018) and a drop in the number of advanced technological developments from 21 units in 2017 up to 3 units in 2019, as well as a decrease in the volume of manufactured innovative goods - 617043.6 million rubles. (a decrease by 2.6\%). In the structure of current expenditures on research and 
development, the negative situation is developing (a decline was $43.7 \%$ compared to the previous period, and in general there was a rollback to the level of the beginning of the 2010s). In the area of "fundamental research", on the contrary, there is an increase in costs by $14.6 \%$ compared to the previous period and by $47.2 \%$ over the last 5 years [33].

In the current conditions, in order to activate the processes of scientific and technological development, it is necessary to strengthen the regional innovation environment by creating a regional accelerator of innovations (Fig. 3). The accelerator should be modified taking into account the specifics of the Udmurt Republic, as a center for the production of weapons and military equipment, where 12 largest Russian military enterprises are located (Kalashnikov, IEMZ Kupol ", Izhevsk Motorcycle Plant" Axion-Holding ", Izhevsk Radio Plant, Votkinsk Plant, Chepetsk Mechanical Plant, Sarapul Electric Generator Plant, etc.).
The mission of the regional innovation accelerator is to develop an innovative environment and technological entrepreneurship in the region, to diversify the military industry.

The goals of acceleration are as follows:

- development of residents' skills and competencies for the effective implementation of entrepreneurial activities in the field of science-intensive technologies;

- experience in the investment market;

- mastering new methods and tools for doing business;

- multiple growth of sales in the Russian and foreign markets;

- improving the quality of innovative projects;

- financing startups;

- popularization of technological entrepreneurship and innovation in the region;

- ensuring the global technological leadership of regional companies.

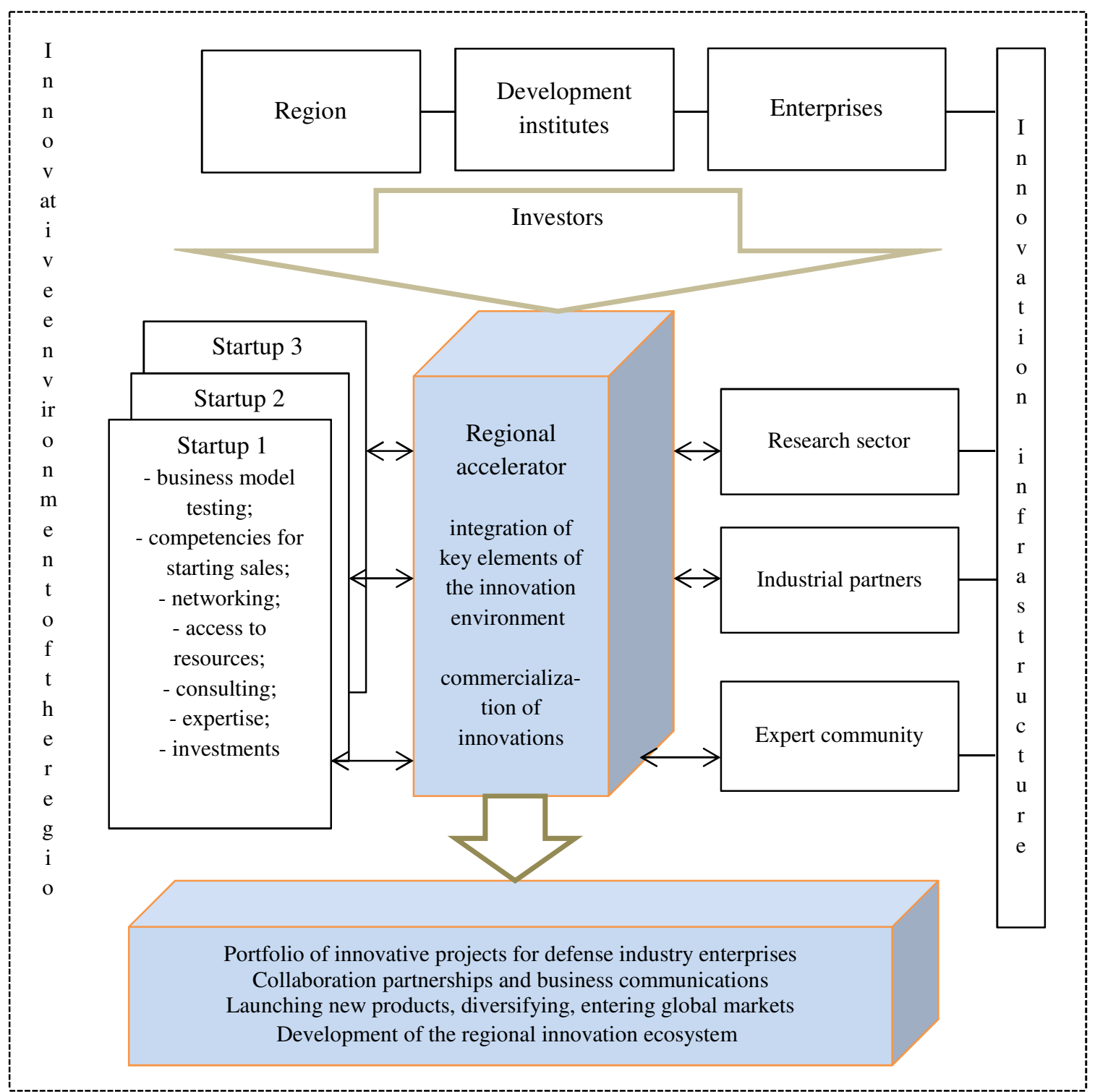

Figure 4. The regional accelerator of innovation in the Udmurt Republic.

The military enterprises employ more than $40 \%$ of the total number of workers in the region. The creation of a regional accelerator focused on the regional defense industry is in line with the federal agenda, according to 
which, since 2017, Russia has been implementing diversification measures in the defense industry by increasing the output of civilian and dual-use products, increasing exports of high-tech products and implementing an import substitution program. By 2030, the share of exports of high-tech civilian products in the total volume of military products should be $50 \%$. In 2020 , the output of the republic's military enterprises amounted to 148 billion rubles. The leading exporters of are military enterprises $(60 \%$ of total exports at the end of 2019), while the pace of diversification lags behind the declared ones. The best performance has been demonstrated by the Axion-Holding Izhevsk Motorcycle Plant, where the volume of civilian products reached 35$40 \%$. Other enterprises are experiencing organizational and technological difficulties. The priority market niches for the defense industry are medicine, radio electronics, power engineering, etc. In terms of the competencies, the capacity of these markets is 1.2 trillion rubles.

Under these conditions, the regional accelerator can become a catalyst for innovation processes, and innovative projects will be funded. Given the growing interest in the "open innovation" paradigm, the regional accelerator can become a platform for implementing the mechanism of "open innovations" - defense industry technologies without the stamp of secrecy, as well as civil technologies with potential dual-uses. Thus, it becomes possible to link the actual needs of the defense industry with the needs of the commercial technology market in the accelerator space.

Since leading business accelerators are interested in projects at the prototyping stage, the value of a regional accelerator can increase in the context of supporting projects at the earliest stages (the "pre-seed" investment round), involving fundamental, exploratory and applied research. At this stage, costs are lower than at subsequent stages of the innovation cycle, which is important in the conditions of investment "vigilance" of the corporate sector and makes it possible for promising ideas to be checked. In world practice, pre-seed investment is the most dynamically growing segment; investors assess the hypotheses of potentially successful companies.

The investment fund of the regional accelerator is formed at the expense of the corporate sector, which is interested in innovations. Regional budget funds can also be attracted; the problem is caused by an unfavorable trend of the budget deficit. Nevertheless, the region has opportunities to facilitate activities of the accelerator in terms of expert, mentoring and organizational support. As a result, the integrative solution of businesses and the government will contribute to the formation of a regional innovation ecosystem. The funds will be used to support the best projects that have passed through the acceleration stage, coworking services, expertise and educational services within the developed program.

The implementation of the acceleration process involves two stages: (AP):

Stage 1. Development of the Acceleration Program

- development of the application form, selection criteria, rules and conditions for the AP;
- development of the site for the AP;

- attraction of participants;

- selection of applications and assessment of AP participants (assessment interviews);

- preparation of companies for implementing the AP (self-diagnostics of companies, work with trackers);

- selection of experts;

- information support of the AP;

- bootcamps (practice-oriented and interactive group sessions with the involvement of mentors and experts, which ensure the involvement of AP participants in the process, form practical skills, abilities and work out design solutions).

The level of expertise and mentoring is crucial. Mentors should be high-skilled specialists. It is difficult to overestimate the amount of support for teams; in a few months, startups travel a path that would otherwise take years. The accelerator methodology provides for an interactive, flexible approach with experimental and competitive components when creating (testing) business models and technologies.

Stage 2. Implementation of the Acceleration Program:

- application of the methods and tools obtained during the bootcamps in the existing business;

- informational coverage of AP events by federal and regional media and Internet resources;

- AP information and consulting block (expert consulting, export tracks, seminars, master classes, business games, case studies);

- practical block of the AP (work accompanied by trackers - mutual exchange of ideas, recommendations and results in a group format);

- expert evaluation of projects (representatives of federal and regional development institutions, the investment sector;

- revision of projects according to experts' comments;

- holding a demo day - the final presentation of AP projects;

- selection of $\mathrm{t}$ winners;

- presentation of certificates to AP finalists.

According to experts, in $30 \%$ of startups, as a result of acceleration, the business model undergoes dramatic changes, the so-called "pivot" occurs. Another $30 \%$ of startups update their metrics. The life cycle of a startup is 18 months, and if there are no attracted investments, the project becomes unprofitable. That is why accelerators are so important for innovators - analysis of ideas, development of technologies and business models, identification and elimination of shortcomings - all processes are much faster and more efficient.

Thus, the AP helps to attract investment, conclude contracts, and receive support for further promotion of projects. An analysis of startups that have successfully gone through the acceleration stage shows that within 1.5 years $30 \%$ of startups raise an investment round, scale up their business and expand partner programs. 


\section{Conclusion}

1. The development of Russian business accelerators is in line with global trends: increased specialization, cooperation with corporations, interest of program residents in international markets, new acceleration formats.

2. The crisis contributed to a significant decrease in the volume of investments of business accelerators in new projects and in the number of concluded deals with startups. At the same time, in 2020 the number of acceleration programs increased due to the active involvement of the corporate sector.

3. The regional level of acceleration is not optimal, $65 \%$ of the regions do not use the acceleration mechanism. The regional authorities should create business accelerators to stimulate the innovation processes.

4. Most of the existing regional accelerators enjoy the support of federal development institutions, regional authorities and business representatives. The role of acceleration in the regional intellectual property market, as well as its consistent integration into the international market system, should be emphasized.

5. Regional accelerators are increasingly focusing on support mechanisms and longer interaction with teams. Industrial partners show interest in pilot implementations and synergies; they want to investment taking into account the possibility of integrating new solutions into the existing production systems.

6 . The model of a regional accelerator of innovations developed for the Udmurt Republic corresponds to the sectoral profile of the region, characterized by a high concentration of military enterprises. The most effective format for the model is a public-private partnership that takes into account interests of the region, innovators, military enterprises and other representatives of the corporate sector.

\section{References}

1. J.D. Christiansen, Copying Y-Combinator: a framework for developing Seed Accelerator programmes, (Individual Project Judge business School \& Jesus College, Cambridge University, Cambridge, 2009)

2. K. Malek, E. Maine, I. McCarthy, Journal of Engineering and Technology Management, 32, 26-39 (2014)

3. D. Hoffman, N. Radojevich-Kelly, Small Business Institute, 8 (2), 54-70 (2012)

4. P. Miller, K. Bound, The startup factories: the rise of accelerator programmes to support new technology ventures (NESTA, London, 2011)

5. M. Szafranski, Business acceleration 21 (2018)

6. H. Etzkowitz, C. Zhou, The triple helix: university-industry-government innovation and enrepreneurship, (Routledge, 2017)
7. H. Etzkowitz, Technol Forecast SOC, 123, 122129 (2017)

8. J. Pique, J. Berbegal-Mirabent, H. Etzkowitz, Triple Helix, 1 (aop), 1-45 (2020)

9. C. Scheel, L. Pineda, Innovacities: Impacto de los sistemas regionales de innovación en las estrategias competitivas de las ciudades, (Universidad Jorge Tadeo Lozano, Bogota, 2015)

10. S. Makarov. E. Ugnich, Foresight-Russia, 9 (1), 56-76 (2015) DOI: 10.17323/1995459X.2015.1.56.67

11. A.A. Sytnik, Bulletin of Saratov State Social and Economic University, 5 (59), 51-54 (2015)

12. M.A. Kamenskikh, Regional Economics: Theory and Practice, 9 (456), 1725-1734 (2018)

13. O.A. Zhdanova, Theory and Practice of Social Development, 12, 76-78, (2016)

14. Yu.V. Fedorova. A.V. Tsvetnykh, Actual problems of aviation and astronautics, 2(9), 348-349, (2013)

15. M.R. Kozlov, Creative economy, 8 (80), 74-82 (2013)

16. D.A. Statovsky, Innovation, 4(198), 49-52 (2015)

17. V.V. Danshina, Bulletin of Belgorod University of Cooperation, Economics and Law, 5, 79-87 (2018) DOI:10.21295/2223-5639-2018-5-79-89

18. Official website «Y-Combinator» Retrieved from: https://www.ycombinator.com/

19. Official website «Seedcamp». Retrieved from: https://seedcamp.com/

20. Yu. Yu. Pavlova, Economics and Business: Theory and Practice, 2-2 (60), 71-78 (2020) DOI: $10.24411 / 2411-0450-2020-10128$

21. Official website of the IIDF Accelerator. Retrieved from: https://accelerator.iidf.ru/

22. The HSE Business Incubator has become the best university accelerator in the world. Retrieved from: https://www.hse.ru/news/edu/316184838.html

23. Review of corporate accelerators 2020. Retrieved from: https://vc.ru/u/495032-sergeykancerov/224726-obzor-korporativnyhakseleratorov-2020-goda

24. Venture capital market in Russia in 2020. Retrieved from: https://incrussia.ru/understand/vc-2020/

25. Who are mentors and why are they needed? Retrieved from: http://www.lookatme.ru/mag/howto/inspiration-howitworks/213055-faq-mentors 
26. Yu.N. Alexandrin, Yu.V. Gorbova, Economics: Theory and Practice, 3 (59), 40-50 (2020)

27. Who and how invested in startups in 2019. Retrieved from: https://incrussia.ru/understand/vc-2019/

28. A.V. Ovchinnikova, Bulletin of the Udmurt University. Series Economics and Law, 2, 61-70 (2014)

29. T.N. Topoleva, Vestnik of the Plekhanov Russian University of Economics, 173 (111), 49-60 (2020) DOI: 10.21686/2413-2829-20203-49-60

30. V.V. Matveev, Bulletin of the Udmurt University. Series Economics and Law, 1 (31), 21-29 (2021) DOI: 10.35634/2412-9593-202131-1-21-29

31. I.I. Rakhmeeva, A.N. Lysenko, Bulletin of PNIPU, 4, 152- 166 (2020)

DOI: $10.15593 / 2224-9354 / 2020.4 .13$

32. V.I. Nekrasov, A.I. Sutygina, P.F. Sutygin et al., Regional economy under WTO conditions, (Russian Academy of Sciences Ural Branch Institute of Economics Udmurt Branch, Yekaterinburg, 2013)

33. Science and innovation: Federal State Statistics Service for UR. Retrieved from: https://udmstat.gks.ru/folder/51964 